\title{
Unusual usage of the automated stapler in gynecologic oncology: method for diaphragmatic full thickness implant resection without entrance to pleural space
}

To the Editor,

The improved survival impact of achieving residue zero cytoreduction were proven in many studies for ovarian carcinoma $(1,2)$. In those, one of the most commonly involved sites is the diaphragm in up to $40 \%$ of cases. Diaphragmatic involvement is one of the most common reasons for the failure to achieve complete or optimal cytoreduction surgery (3). Although there has been improvements in technique, experience, and education over the years, there are still concerns about complications and management of diaphragmatic tumor resection, especially in the presence of full thickness implants. Therefore, we would like to describe a technique for resection of diaphragm full thickness implants without entrance to the pleural space. Firstly, the liver was mobilized. Diaphragm striping was performed up to the full thickness implant. When an unresectable area was reached, the following technique was performed to resect the full thickness implant. The steps of the technique were: (i) after identification of the full thickness implant borderlines, sutures were placed to the medial, middle and lateral edges of the full thickness implant to more easily perform traction (Figure 1); (ii) an automated stapling device, such as thoraco-abdominal stapler DST series ${ }^{\mathrm{TM}}$ (Figure 2) or gastro-intestinal anastomosis stapler (DST series ${ }^{\mathrm{TM}}$ ) were placed transversally to diaphragm, under the full thickness implant which had been displaced by traction; (iii) in order to avoid lung parenchymal injury, the ventilator was temporarily turned off after exhalation, while the stapler was locked up; (iv) the stapler was locked up to place the sutures automatically; (v) the full thickness implant above the staplers was resected via manual scalpel for thoraco-abdominal stapler or by the integrated automated scalpel for gastro-intestinal anastomosis stapler, and the stapler was opened; (vi) the resection was completed without entrance to pleural space; and (vii) final control for air leakage using a bubble test, was performed. There were either no, or minimal, asymptomatic pleural

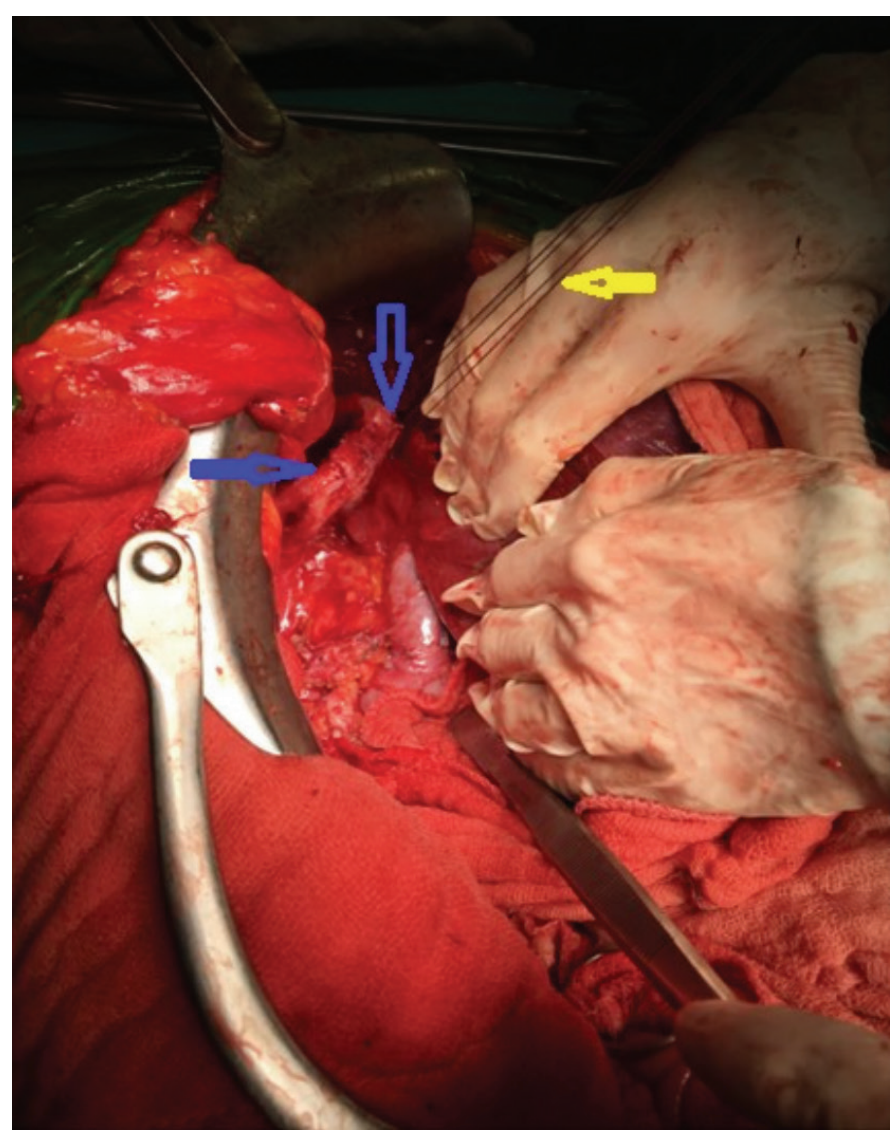

Figure 1. Sutures placed to the medial edge, the middle and the lateral edge of the full thickness implant to perform traction easier 


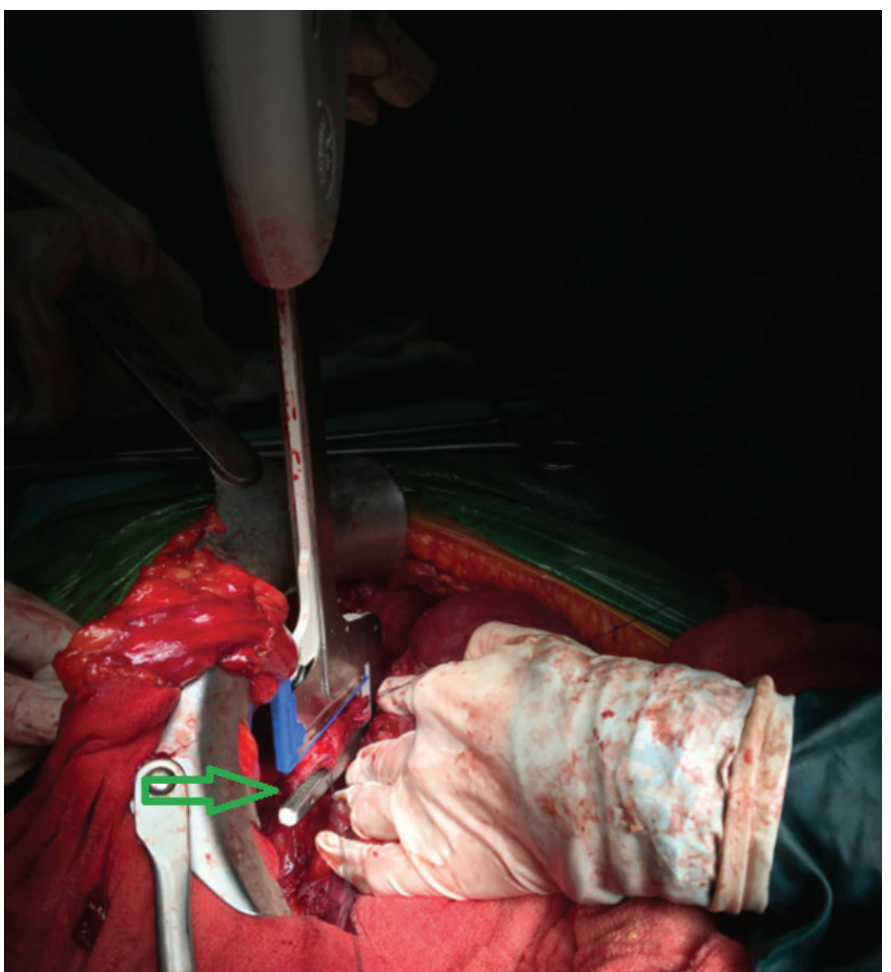

Figure 2. Thoraco-abdominal stapler (DST series ${ }^{\mathrm{TM}}, 30$ mm) was placed under the hauled full thickness implant transversally to diaphragm

effusion, and no pneumothorax. There was also no need for thoracentesis during the postoperative period in both patients in our institution. Diaphragmatic muscle invasion of a highgrade, serous ovarian carcinoma was reported in pathologic results [institutional review board (approval number: 07/2019/90057706-799)].

One of the concerns when undertaking diaphragmatic full thickness implant resection is pulmonary complication. Additionally, entrance to the pleural cavity increases the possibility of prophylactic chest tube application $(4,5)$. The technique described here may have an advantage in minimizing the occurrence of pneumothorax and the amount of pleural effusion by avoiding pleural entrance. Thus, this may encourage less use of a prophylactic chest tube, decrease the need for thoracentesis, and also lessen postoperative morbidity. Our technique may also make diaphragmatic full thickness implant resection viable as part of minimally invasive surgeries. The undeniable fact that the operation time is longer in the presence of diaphragmatic full thickness implant resection in contrast to striping, because of the need for manual closure by suture. This technique may have an additional advantage in decreasing operation time because of automatically suturing. Kapnick et al. (6) showed that the probability of pleural/ parenchymal involvement was higher in the presence of more than $5 \mathrm{~cm}$ full thickness implant. Therefore, we believe that this technique may be a good option in $<4 \mathrm{~cm}$ full thickness implants.

To the best of our knowledge, this is the first report of the usage of a thoraco-abdominal stapler for resection of diaphragmatic full thickness implant without entrance to the pleural space. Diaphragmatic full thickness implant resection with stapler appears to be safe, practical and an easy to learn surgical technique. There is a need for large scale studies to evaluate the conclusions of this technique.

\section{Günsu Kimyon Cömert, Alper Karalok, Ciğdem Kılıç, Derman Başaran, Fatih Kılıç, Osman Türkmen, Taner Turan}

\section{Clinic of Obstetrics and Gynecology, University of Health Sciences Turkey, Ankara Etlik Zübeyde Hanım Women's Health Training and Research Hospital, Ankara, Turkey}

\section{References}

1. Manning-Geist BL, Hicks-Courant K, Gockley AA, Clark RM, De Carmen MG, Growdon WB, et al. Moving beyond "complete surgical resection" and "optimal": Is low-volume residual disease another option for primary debulking surgery? Gynecol Oncol 2018; 150: $233-8$

2. Tseng JH, Cowan RA, Zhou Q, Iasonos A, Byrne M, Polcino T, et al. Continuous improvement in primary Debulking surgery for advanced ovarian cancer: Do increased complete gross resection rates independently lead to increased progression-free and overall survival? Gynecol Oncol 2018; 151: 24-31.

3. Eisenkop SM, Spirtos NM. What are the current surgical objectives, strategies, and technical capabilities of gynecologic oncologists treating advanced epithelial ovarian cancer? Gynecol Oncol 2001; 82: 489-97.

4. Franssen B, Tabrizian P, Weinberg A, Romanoff A, Tuvin D, Labow $\mathrm{D}$, et al. Outcome of cytoreductive surgery and hyperthermic intraperitoneal chemotherapy on patients with diaphragmatic involvement. Ann Surg Oncol 2015; 22(5): 1639-44.

5. Chéreau E, Rouzier R, Gouy S, Ferron G, Narducci F, Bergzoll C et al. Morbidity of diaphragmatic surgery for advanced ovarian cancer: retrospective study of 148 cases. Eur J Surg Oncol 2011; 37: $175-80$.

6. Kapnick SJ, Griffiths CT, Finkler NJ. Occult pleural involvement in stage III ovarian carcinoma: role of diaphragm resection. Gynecol Oncol 1990; 39: 135-8. 